\title{
A patient with hypereosinophilic syndrome that manifested with acquired hemophilia and elevated IgG4: a case report
}

\author{
Yoshiro Nagao $^{1 *}$, Hiromi Yamanaka ${ }^{2}$ and Hiromasa Harada ${ }^{1}$
}

\begin{abstract}
Introduction: Hypereosinophilic syndrome is defined as a prolonged state (more than six months) of eosinophilia (greater than 1500 cells/ $/ \mathrm{L}$ ), without an apparent etiology and with end-organ damage. Hypereosinophilic syndrome can cause coagulation abnormalities. Among Hypereosinophilic syndrome types, the lymphocytic variant (lymphocytic Hypereosinophilic syndrome) is derived from a monoclonal proliferation of T lymphocytes. Here, we describe the case of a patient with lymphocytic Hypereosinophilic syndrome who presented with a coagulation abnormality. To the best of our knowledge, this is the first such report including a detailed clinical picture and temporal cytokine profile.
\end{abstract}

Case presentation: A 77-year-old Japanese man presented to our facility with massive hematuria and hypereosinophilia (greater than 2600 cells/ $\mu$ l). His eosinophilia first appeared five years earlier when he developed femoral artery occlusion. He manifested with multiple hematomas and prolonged activated partial thromboplastin time. His lgG4 level was remarkably elevated (greater than 2000 mg/dL). Polymerase chain reaction tests of peripheral blood and bone marrow identified lymphocytic Hypereosinophilic syndrome. His prolonged activated partial thromboplastin time was found to be due to acquired hemophilia. Glucocorticoids suppressed both the hypereosinophilia and coagulation abnormality. However, tapering of glucocorticoids led to a relapse of the coagulation abnormality alone, without eosinophilia. Tumor necrosis factor $\alpha$, interleukin-5, and/or eotaxin-3 may have caused the hypereosinophilia, and interleukin-10 was correlated with the coagulation abnormality.

Conclusions: To the best of our knowledge, this is the first case in which lymphocytic Hypereosinophilic syndrome and IgG4-related disease have overlapped. In addition, our patient is only the second case of hypereosinophilic disease that manifested with acquired hemophilia. Our patient relapsed with the coagulation abnormality alone, without eosinophilia. This report shows that the link between eosinophilia, lgG4, and clinical manifestations is not simple and provides useful insight into the immunopathology of Hypereosinophilic syndrome and lgG4-related disease.

\section{Introduction}

Hypereosinophilic syndrome (HES) was originally proposed as a state of (i) blood eosinophilia with an absolute eosinophil count greater than $1500 \mathrm{cells} / \mu \mathrm{L}$ and persisting for more than six months, (ii) without an apparent etiology (for example, parasitic infection or allergic disease), and (iii) with eosinophil-mediated organ dysfunction [1]. Currently, HES is classified based

\footnotetext{
* Correspondence: in_the_pacific214@yahoo.co.jp 'Department of Internal Medicine, Yao Tokushukai General Hospital, 1-11 Wakakusa-cho, Yao city, Osaka, 581-0011, Japan

Full list of author information is available at the end of the article
}

on etiology [2]. For example, the lymphocytic variant (LHES) is derived from a monoclonal proliferation of $\mathrm{T}$ lymphocytes. T cell clones identified in L-HES often express aberrant immunophenotypes (for example, CD3CD4+, CD3+CD4-CD8-, CD4+CD7-, CD16+CD56+) [3-6], although no aberrancy has been identified in many patients with L-HES [7]. In contrast, the myeloproliferative variant (M-HES) is characterized by emergence of fusion genes (for example, PDGFRa, PDGFR $b$, and FGFR1) originating from a chromosomal translocation in $4 \mathrm{q} 12,5 \mathrm{q} 33$, and $8 \mathrm{p} 11$, respectively [8]. HES affects not only diverse organs, but also causes

\section{Biomed Central}


thrombotic occlusion in arteries $[9,10]$, veins [11-14], and capillaries [15]. In addition, patients with HES present with coagulation abnormalities, especially disseminated intravascular coagulation (DIC), possibly due to this thrombotic tendency $[9,14,16-18]$. However, the mechanism of HES-derived coagulation abnormality is not fully understood.

\section{Case presentation}

A 77-year-old Japanese man presented to the outpatient department of our hospital (day one) with hematuria $(42,000$ red blood cells $/ \mu \mathrm{L})$ and a hematoma under the jaw. He had anemia (hemoglobin (Hb) $9.3 \mathrm{~g} / \mathrm{dL}$ ), and a remarkable eosinophilia (2600 cells $/ \mu \mathrm{L} ; 32 \%$ of white blood cells) (Figure 1a). He had a history of minor bronchial asthma, which had been treated with an inhaled glucocorticoid and an anticholinergic. His medical records also showed a history of hypereosinophilia five years earlier, when he developed femoral artery occlusion. He was prescribed warfarin $2 \mathrm{mg} /$ day after the associated bypass surgery. In spite of this history, vascular risk factors (diabetes mellitus, hypertension, and hyperlipidemia) were absent. At presentation, renal damage ( $\beta 2$-macroglobulin $9.5 \mathrm{mg} / \mathrm{L}$, normal range 0.9 to $1.9 \mathrm{mg} / \mathrm{L}$ ) was recognized. High levels of $\operatorname{IgG}$ and $\operatorname{IgE}$ (Figure $1 \mathrm{~g}$ ) were also noted. IgA $(90 \mathrm{mg} / \mathrm{dL})$ and $\mathrm{IgM}$ $(36 \mathrm{mg} / \mathrm{dL}$ ) were within normal ranges. While his platelet count $(169,000$ cells $/ \mu \mathrm{L})$ and bleeding time (one and a half minutes, normal range one to three minutes) were normal, coagulation times were remarkably prolonged: the activated partial thromboplastin time (APTT) was 68 seconds (normal: 25 to 40 seconds) and the prothrombin time-international normalized ratio (PT-INR) was 1.65 (Figure 1c,d). Since hematuria and hematoma were assumed to be due to this coagulopathy, warfarin was stopped.

We considered bronchial asthma, eosinophilic pneumonia, Churg-Strauss syndrome (CSS), malignancies [19], parasitic infections, adrenal insufficiency, and HES as differential diagnoses to explain this eosinophilia. However, his minor bronchial asthma did not explain the high level of eosinophilia. Since a computed tomography (CT) scan detected no abnormalities in the lungs, eosinophilic pneumonia was excluded. Among six diagnostic criteria for CSS, only asthma and eosinophilia were fulfilled [20]. In addition, tests for anti-neutrophil cytoplasmic antibodies (ANCAs) were negative. Therefore, CSS was unlikely. Tumor markers were measured (carcinoembryonic antigen (CEA), squamous cell carcinoma (SCC), $\alpha$-fetoprotein (AFP), and protein induced by vitamin $\mathrm{K}$ absence 2 (PIVKA2)) and M-protein findings were all negative. There were no parasitic eggs or larvae in his stool, and results of sera anti-Aspergillus antibody tests were negative. His cortisol level was within the normal range on repeated measurements; hence, adrenal insufficiency was considered unlikely. Based on these results, HES remained as the most likely diagnosis. To categorize the HES, monoclonality in the $\mathrm{T}$ cell receptor (TCR) was examined by polymerase chain reaction (PCR) [21] (Mitsubishi Medience, Tokyo, Japan), using peripheral blood and bone marrow aspirate. Subsequently, in both samples, TCR monoclonality was detected in $\beta, \gamma$, and $\delta$ chains (Table 1). This finding supported the diagnosis of L-HES. Consistent with this diagnosis, multiple enlarged lymph nodes near the abdominal aorta were detected on CT scan (Figure 2). In contrast, no chromosome abnormality was detected in the bone marrow aspirates. In addition, fluorescence in situ hybridization (FISH) analysis of peripheral blood and bone marrow aspirates did not detect $4 \mathrm{q} 12$ translocation, the most frequent translocation associated with M-HES. Therefore, M-HES was less likely [2]. Collectively, these findings pointed to a diagnosis of L-HES.

After warfarin was stopped from day one, his PT-INR steadily normalized (Figure 1d). However, APTT continued to be prolonged (Figure 1c). Although our patient tested positive for anti-hepatitis $\mathrm{B}$ core $(\mathrm{HBc})$ and antihepatitis $\mathrm{C}$ virus (HCV) antibodies, hepatitis B surface (HBs) antigen, hepatitis B virus (HBV) DNA and $\mathrm{HCV}$ RNA were all undetectable. Transaminases were consistently within the normal range. Ultrasonography, CT, and MRI scans did not detect any abnormality in the liver. Hence, the liver was not the source of the prolonged APTT. Other causes of a coagulation abnormality (such as protein $\mathrm{C}$ and/or $\mathrm{S}$ deficiencies, systemic lupus erythematosus, and anti-phospholipid antibody syndrome) were excluded (data not shown). Although the possibility of DIC was suggested (fibrin degradation products (FDP) $18 \mu \mathrm{g} / \mathrm{mL}$, D-dimer $7.4 \mu \mathrm{g} / \mathrm{mL}$, antithrombin III $66 \%$, platelet count 117,000 cells $/ \mu \mathrm{L}$ ), ultrasonography detected no thrombus in the heart or veins/ arteries of the lower limbs. Taken together, the findings suggested the prolonged APTT in our patient most likely originated from his HES.

On day 28, our patient developed a subcutaneous hematoma in his hip, which spread rapidly to the thighs, and he was admitted to our hospital. His APTT was further prolonged (83 seconds; Figure 1c). Hematomas appeared on his trunk and upper limbs. His oral mucosa and a scar in his ear began to bleed. Although a large amount of fresh frozen plasma and red blood cells were infused between days 31 and 34, his APTT reached a high of 93 seconds on day 36, and the hemoglobin level decreased to $7.9 \mathrm{~g} / \mathrm{dL}$ (Figure 1c,f). On day 36, prednisolone was started at $60 \mathrm{mg} /$ day (Figure $1 \mathrm{~b}$ ). His peripheral eosinophils decreased quickly (Figure 1a). The APTT and platelet count gradually normalized (Figure 1c,e), while bleeding, subcutaneous hematomas, 
(a) Eosinophilia

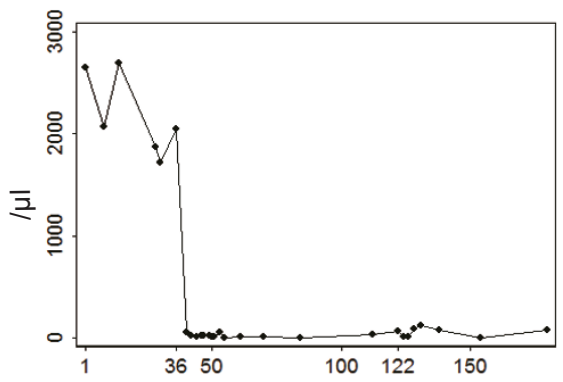

(c) Activate Partial Thromboplastin Time

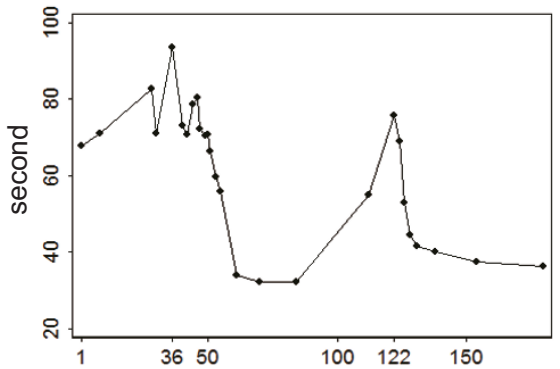

(e) platelet count

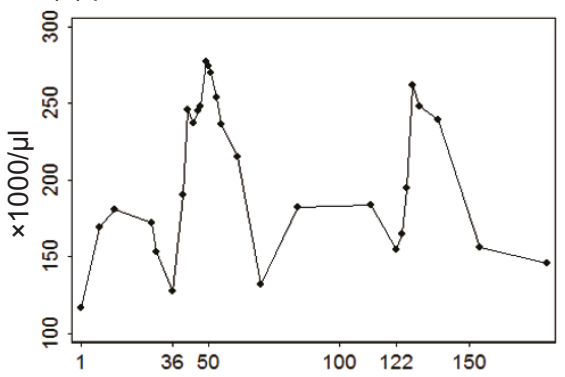

(g) $\lg G$, IgG4 and $\lg E$

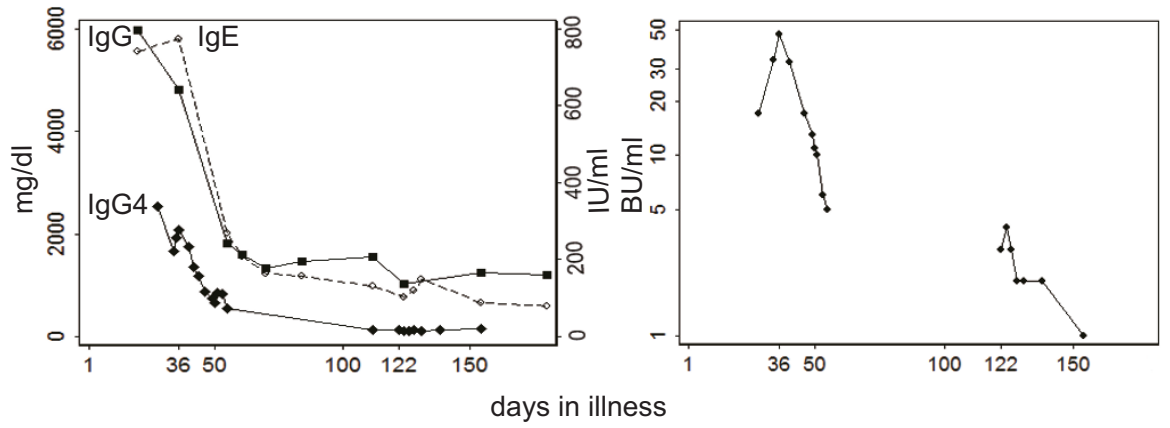

(b) Prednisolone

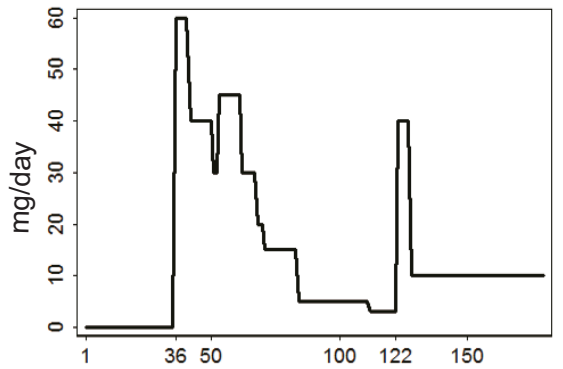

(d) PT-INR

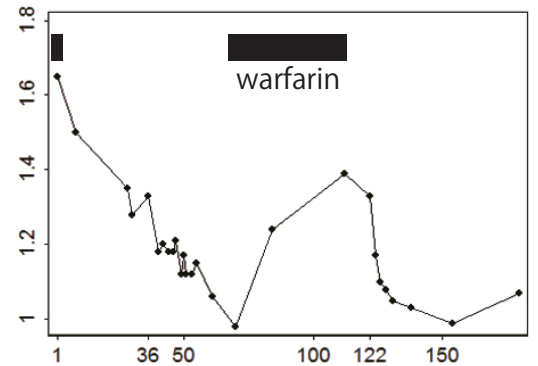

(f) Hemoglobin

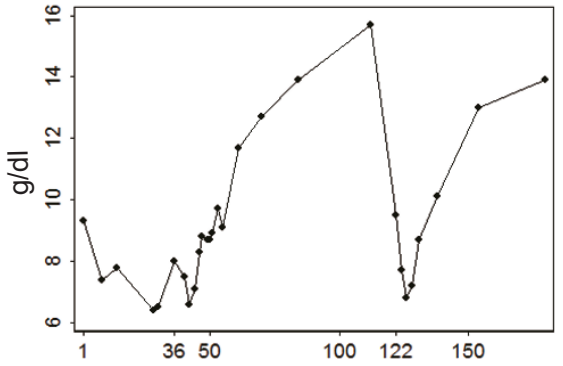

(h) Anticoagulant to Factor VIII (intravenous and oral), (c) activated partial thromboplastin time, (d) prothrombin time-international normalized ratio (PT-INR), (e) platelet count, (f) hemoglobin level, (g) $\operatorname{lgG}, \operatorname{lgG} 4(\mathrm{mg} / \mathrm{dL})$ and $\mathrm{lgE}(\mathrm{IU} / \mathrm{mL})$, and $(\mathbf{h})$ anticoagulant to factor VIII, are plotted above the time axis.

hematuria, and anemia subsided steadily (Figure 1f). Renal damage improved ( $\beta 2$-macroglobulin decreased to $3.4 \mathrm{mg} / \mathrm{L}$ ). A CT scan revealed that the lymph nodes around the abdominal aorta had shrunk to a normal size (data not shown). His $\gamma$-globulinemia normalized (Figure 1g). He was discharged on day 55. Prednisolone was continuously tapered in the out-patient setting (Figure $1 b)$.

On day 122, when the dose of prednisolone was down to $3 \mathrm{mg} /$ day, a subcutaneous hematoma developed in his thigh. Although his eosinophil count was normal at 64 cells $/ \mu \mathrm{L}$ ( $0.4 \%$ of the total white blood cells), his 
Table 1 Monoclonalities detected by polymerase chain reaction (PCR) in the $\mathrm{T}$-cell receptor genes

\begin{tabular}{llll}
\hline Chain & $\begin{array}{l}\text { Region to which PCR was } \\
\text { applied }\end{array}$ & $\begin{array}{l}\text { Bone } \\
\text { marrow }\end{array}$ & $\begin{array}{l}\text { Peripheral } \\
\text { blood }\end{array}$ \\
\hline$\beta$ & $V \beta / J \beta 1,2$ & Positive & Positive \\
Chain & $V \beta / J \beta 2$ & Positive & Positive \\
& $D \beta / J \beta$ & Positive & Positive \\
$\gamma$ & $V \gamma \mid f, V \gamma 10 / J \gamma$ & Positive & Positive \\
Chain & & Positive & Positive \\
& $V \gamma 9, V \gamma 11 / J \gamma$ & Positive & Marginal \\
$\begin{array}{ll}\delta \\
\text { Chain }\end{array}$ & $V \delta / J \delta$ & & \\
\hline
\end{tabular}

Positive: monoclonality was detected. Marginal: the peak of PCR was noticeable but its height was lower than the positive control. The methodology is described in detail in [21].

APTT was again prolonged (76 seconds, Figure 1c). He was admitted to our hospital again, where prednisolone was raised to $40 \mathrm{mg} /$ day (Figure $1 \mathrm{~b}$ ). Since his APTT then normalized and hematoma diminished steadily, he was discharged on day 141. To date, he has been kept on prednisolone at $10 \mathrm{mg} /$ day, with no further relapses of coagulopathy or peripheral hypereosinophilia.

To investigate the prolonged APTT, coagulation factors V to XII were measured. Consequently, the activity of factor VIII was markedly reduced: $4 \%$ on day 122 (the day of relapse onset). Other factors were all within normal ranges (data not shown). To examine the pathogenesis of the coagulopathy, we preserved our patient's sera $\left(\right.$ at $-80^{\circ} \mathrm{C}$ ) taken after day 34 . Control sera were also obtained from 10 healthy individuals (ages 29 to 59 years old, five men, five women).

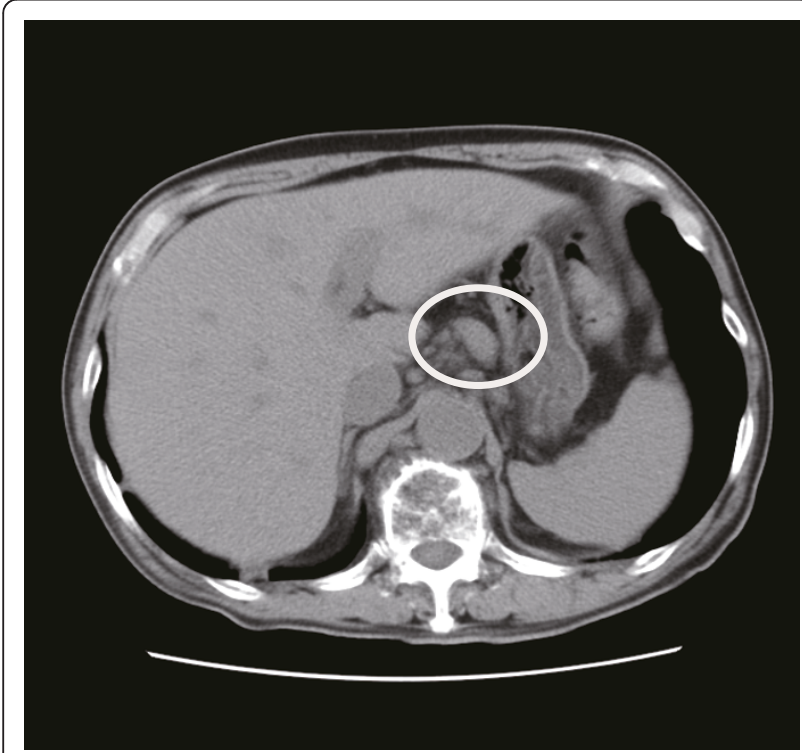

Figure 2 Enlarged lymph nodes near the abdominal aorta at the onset of illness. The enlarged lymph nodes are indicated.
Written informed consent was obtained from all individuals. The research protocol was approved by the committee for clinical ethics of Yao Tokushukai General Hospital. Circulating anticoagulant against factor VIII was evaluated in the preserved sera by using the Bethesda assay. As a result, our patient's anticoagulant level was found to be elevated during both the initial and relapse episodes: $47 \mathrm{BU} / \mathrm{mL}$ on day $36,4 \mathrm{BU} / \mathrm{mL}$ on day 124 (Figure 1h), while anticoagulant was not detected in any of the control sera. Furthermore, the result of a cross-mixing test conducted on day 122 was not inconsistent with acquired hemophilia (that is, acquisition of anticoagulant) (Figure 3). Our patient and his parents had no history of bleeding abnormalities, which excluded hereditary hemophilia. Therefore, acquired hemophilia was the most likely diagnosis. Other than anticoagulant against factor VIII, all the autoantibodies examined (including anti-nuclear, antiSjögren's syndrome A/B (SS-A/B), anti-thyroglobulin, anti-thyroid peroxidase, and anti-DNA antibodies) showed normal values.

To illustrate the immunological dynamics in our patient, 15 cytokines in the sera were measured by using a Milliplex assay (Millipore, Billerica, MA, USA) (Figure 4). To examine the possible involvement of IgG4-related disease (IgG4RD), a newly recognized disease entity [22], we measured IgG4 in the preserved serum. IgG4 showed a disproportionately high value (Figure $1 \mathrm{~g}$ ). For example, on day 36, IgG4 was $2070 \mathrm{mg} / \mathrm{dL}$ (normal range 4.8 to $105 \mathrm{mg} / \mathrm{dL}$ ), which constituted $48 \%$ of the total IgG (normal value $<7 \%$ ).

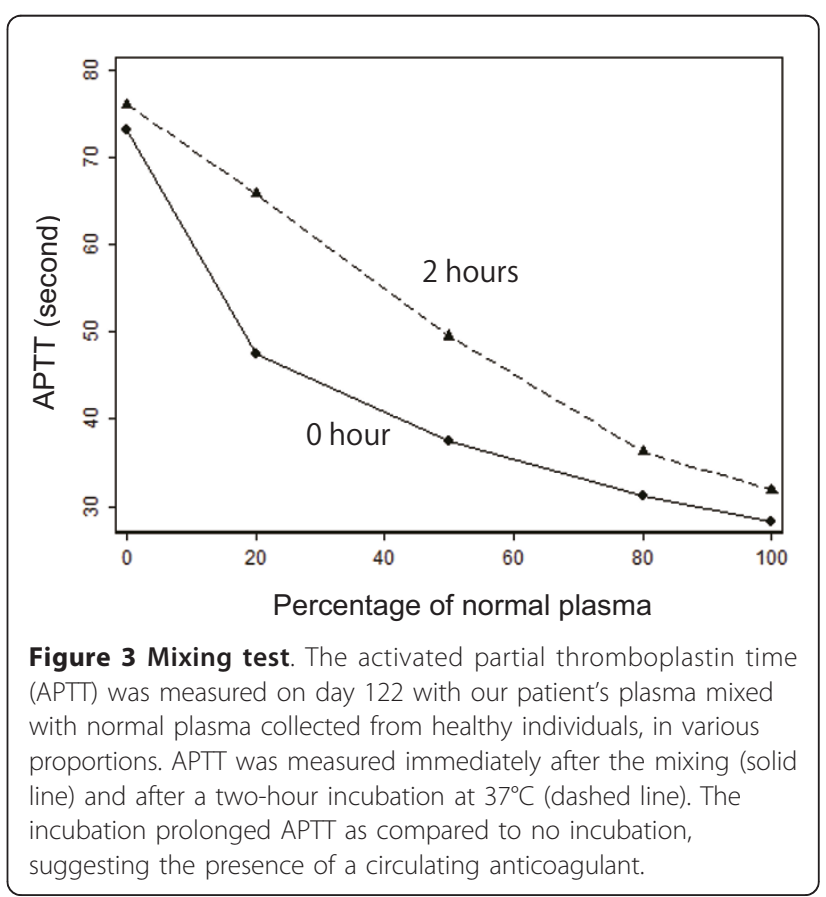


(a) TNF-alpha

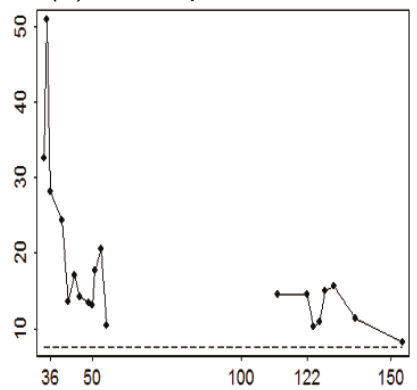

(d) IL-10

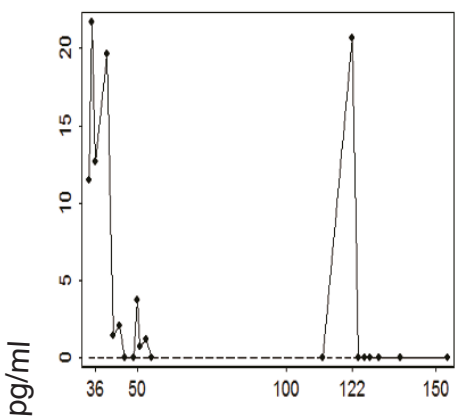

(g) IL-13

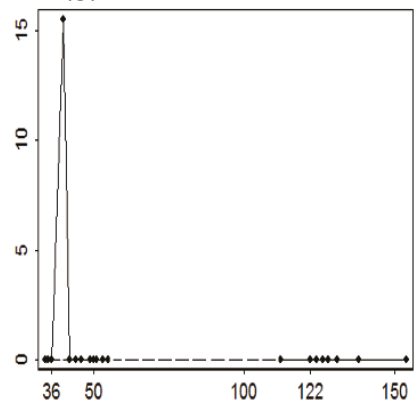

(j) G-CSF

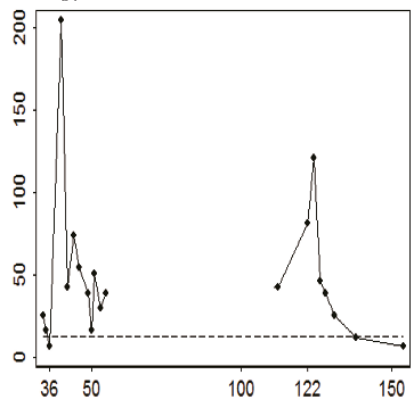

(b) IL-5

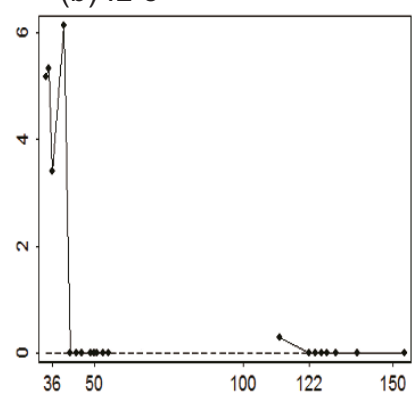

(e) IL-6

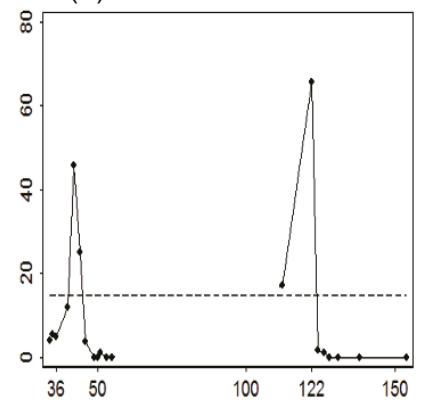

(h) GM-CSF

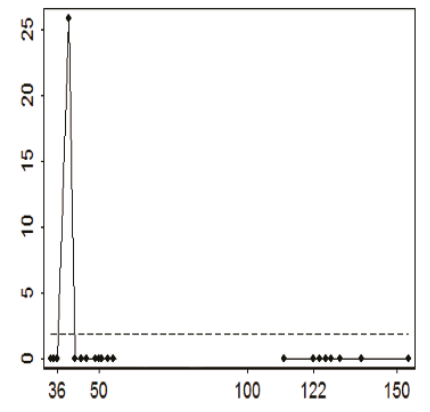

(k) eotaxin-1

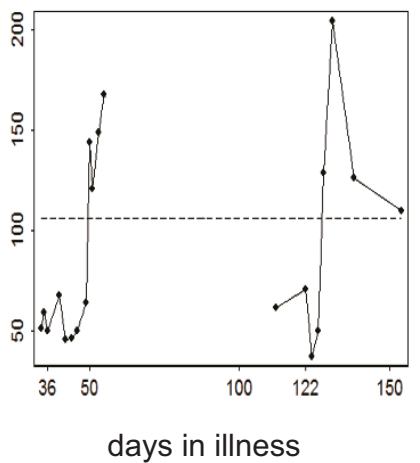

(c) eotaxin-3

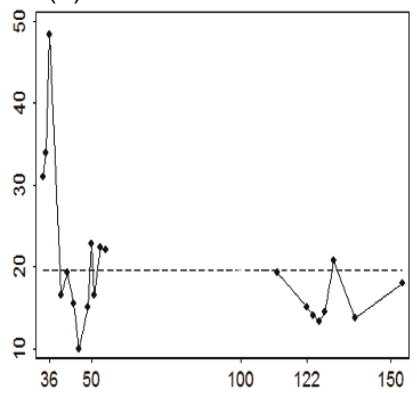

(f) IL-15

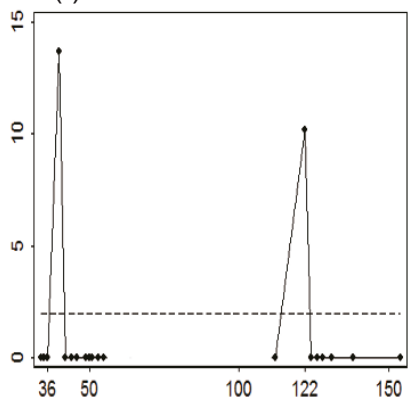

(i) IL-2

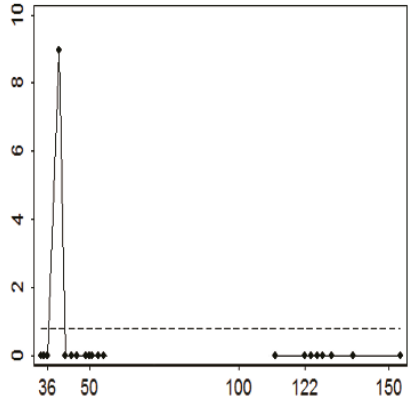

Figure 4 Temporal profile of cytokines in our patient's sera. The following 15 cytokines were measured in the sera taken after day 34 : interleukin (IL)-2, IL-3, IL-4, IL-5, IL-6, IL-10, IL-13, IL-15, IL-17, eotaxin-1, eotaxin-3, granulocyte colony stimulating factor (G-CSF), granulocytemacrophage colony stimulating factor (GM-CSF), tumor necrosis factor $\alpha$ (TNF $\alpha$ ), and interferon $\gamma$ (IFN $\gamma$ ). The dashed line in the each panel represents the upper limit of the 95\% confidence interval (95\% Cl) estimated from the healthy controls. Day 36 (when prednisolone was started at $60 \mathrm{mg} /$ day) and day 122 (when prednisolone was raised from $3 \mathrm{mg} /$ day to $40 \mathrm{mg} /$ day) are specifically labeled on the time axis. IL-3, IL-4, IL17, and IFN $\gamma$, which were consistently within the $95 \% \mathrm{Cl}$ of controls, were thus omitted. 


\section{Discussion}

We report a case of a patient with L-HES who manifested with a coagulation abnormality. Glucocorticoids effectively suppressed hypereosinophilia and corrected the coagulation abnormality. However, excessive subsequent tapering of the glucocorticoid brought about a relapse of the coagulation abnormality, but not the eosinophilia.

It has been reported that HES can manifest with thrombotic tendency. Our patient had developed femoral artery occlusion, a frequent manifestation of HES-induced thrombosis, five years prior to the episode reported here. The thrombotic tendency had been controlled effectively by warfarin. In the episode reported here, factor VIII activity was remarkably decreased, which was most likely due to acquired hemophilia. Hypereosinophilia complicated with acquired hemophilia has been reported only once previously in the literature [23]. In our patient, DIC, a frequent complication of HES $[9,14,16-18]$, possibly exacerbated the bleeding tendency. These findings remain to be generalized to other cases of HES-derived coagulopathy.

Our patient's case, featuring an extremely high value of IgG4, is likely to be an example of IgG4RD. IgG4RD, first reported in 1993 [24], is characterized by elevated serum IgG4 and/or tissue infiltration by IgG4+ plasma cells $[25,26]$. IgG4RD has been recognized as a systemic illness which affects numerous organs including lymph nodes [24], pancreas [25], salivary gland [24,26], retroperitoneum [27], and kidney [28]. Its pathogenesis, however, remains to be elucidated [22]. IgG4RD has been often associated with eosinophilia [29-31], and responds well to glucocorticoid [22]. These characteristics are consistent with our patient, supporting the diagnosis of IgG4RD in this case. To the best of our knowledge, the presented case is the first reported example in which LHES and IgG4RD have overlapped.

The cytokines measured in our patient's sera can be classified into three groups in relation to the illness (Figure 4). First, tumor necrosis factor $\alpha$ (TNF $\alpha$ ), interleukin (IL)5 , and eotaxin-3 increased to very high levels immediately before the first episode, and decreased to low levels after the glucocorticoid was started on day 36 . Therefore, these cytokines were correlated with eosinophilia. Second, IL-10 was present at very high levels until glucocorticoid was started on day 36, and peaked again at the onset of relapse. Hence, IL-10 exhibited a strong correlation with prolonged APTT and anticoagulant to factor VIII. Third, other cytokines in Figure 3 rose to high levels immediately after day 36. These peaks may possibly be reactions to substances released from dying eosinophils $[9,18]$. Among the cytokines in this group, granulocyte colony stimulating factor (G-CSF) and eotaxin-1 showed second elevations in the relapse phase, suggesting heterogeneity within this group. The roles of these cytokines in the pathogenesis are difficult to explain. Collectively, TNF $\alpha$, IL-5, and eotaxin-3 appeared to play an important role in generating peripheral hypereosinophilia, while IL-10 was most closely correlated with prolonged APTT and anticoagulant. Indeed, eosinophilic diseases have been associated with TNF $\alpha$ [32,33], IL-5 [34], IL-10 [35], and eotaxin-3 [36,37], while IL-10 was overexpressed in IgG4RD [38,39]. The causal relationship between these cytokines, eosinophilia, IgG4, and clinical manifestations remains to be elucidated.

\section{Conclusions}

To the best of our knowledge, this is the first case of LHES overlapped with IgG4RD, and the second reported case of hypereosinophilic disease complicated by acquired hemophilia. Furthermore, this is the first case of L-HES or IgG4RD in which the cytokine profile was described during the phases of onset and relapse. Although the clinical manifestation (that is, coagulopathy) presented twice (in the first episode and in the relapse), the underlying immunological profiles were dissimilar between these two periods. These findings imply that the interaction between HES and IgG4RD is a complex process.

\section{Consent}

Written informed consent was obtained from the patient for publication of this case report and any accompanying images. A copy of the written consent is available for review by the Editor-in-Chief of this journal.

\section{Acknowledgements}

We are grateful to Yasushi Teranishi, Kazuyuki Yoshizaki, Ayalew Tefferi, and Masayuki Miyata for their cooperation and advice. We are happy to provide the sera from our patient to those who may wish to validate our results. All the laboratory data, from which the identification information was deleted, are available from the corresponding author upon request.

\section{Author details}

'Department of Internal Medicine, Yao Tokushukai General Hospital, 1-11 Wakakusa-cho, Yao city, Osaka, 581-0011, Japan. ²Department of Pathology, Yao Tokushukai General Hospital, 1-11 Wakakusa-cho, Yao city, Osaka, 5810011, Japan.

\section{Authors' contributions}

YN analyzed and interpreted the data from our patient regarding the hypereosinophilic syndrome. HY performed all of the examinations, including hematological and immunological, and took responsibility for data management. $\mathrm{HH}$ took responsibility for the clinical management of our patient. All authors read and approved the final manuscript.

\section{Competing interests}

The authors declare that they have no competing interests.

Received: 12 August 2011 Accepted: 14 February 2012

Published: 14 February 2012

\section{References}

1. Chusid MJ, Dale DC, West BC, Wolff SM: The hypereosinophilic syndrome: analysis of fourteen cases with review of the literature. Medicine (Baltimore) 1975, 54:1-27. 
2. Roufosse F, Klion A, Weller P: Clinical manifestations, pathophysiology, and diagnosis of the hypereosinophilic syndromes, UpToDate; 2011. [http://www.uptodate.com].

3. Cogan E, Schandene L, Crusiaux A, Cochaux P, Velu T, Goldman M: Brief report: clonal proliferation of type 2 helper T cells in a man with the hypereosinophilic syndrome. N Engl J Med 1994, 330:535-538.

4. Simon HU, Yousefi S, Dommann-Scherrer CC, Zimmermann DR, Bauer $S$, Barandun J, Blaser K: Expansion of cytokine-producing CD4-CD8- T cells associated with abnormal Fas expression and hypereosinophilia. J Exp Med 1996, 183:1071-1082.

5. Simon HU, Plotz SG, Dummer R, Blaser K: Abnormal clones of T cells producing interleukin-5 in idiopathic eosinophilia. N Engl J Med 1999, 341:1112-1120.

6. Means-Markwell M, Burgess T, de Keratry D, O'Neil K, Mascola J, Fleisher T, Lucey D: Eosinophilia with aberrant T cells and elevated serum levels of interleukin-2 and interleukin-15. N Engl J Med 2000, 342:1568-1571.

7. Helbig G, Wieczorkiewicz A, Dziaczkowska-Suszek J, Majewski M, KyrczKrzemien S: T-cell abnormalities are present at high frequencies in patients with hypereosinophilic syndrome. Haematologica 2009, 94:1236-1241.

8. Tefferi A, Gotlib J, Pardanani A: Hypereosinophilic syndrome and clonal eosinophilia: point-of-care diagnostic algorithm and treatment update. Mayo Clin Proc 2010, 85:158-164.

9. Nagashima M, Nishizawa M, Yamauchi T, Mori S, Honma Y: A case of the idiopathic hypereosinophilic syndrome presenting with mononeuritis multiplex, multiple thrombosis, and disseminated intravascular coagulation [in Japanese]. Rinsho Shinkeigaku 1986, 26:698-703.

10. Kawata E, Kuroda J, Wada K, Yoshida M, Kamiuchi K, Nakayama-Harusato I, Kimura S, Maekawa T, Kitagawa Y: Hypereosinophilic syndrome accompanied by Buerger's disease-like femoral arterial occlusions. Intern Med 2007, 46:1919-1922.

11. Kojima K, Sasaki T: Veno-occlusive disease in hypereosinophilic syndrome. Intern Med 1995, 34:1194-1197.

12. Schulman H, Hertzog L, Zirkin H, Hertzanu Y: Cerebral sinovenous thrombosis in the idiopathic hypereosinophilic syndrome in childhood. Pediatr Radiol 1999, 29:595-597.

13. Sherer Y, Salomon O, Livneh A, Pras M, Langevitz P: Thromboembolism in a patient with transient eosinophilia and thrombocytopenia. Clin Lab Haematol 2000, 22:247-249

14. Miyagi J, Ichimiya M, Ozaki K, Goto T, Fujino O, Nagata J, Hiasa Y: Hypereosinophilic syndrome complicated by disseminated intravascular coagulation (DIC), deep venous thrombosis and pulmonary embolism [in Japanese]. Nihon Naika Gakkai Zasshi 2004, 93:364-366.

15. Amini R, Nielsen C: Eosinophilic myocarditis mimicking acute coronary syndrome secondary to idiopathic hypereosinophilic syndrome: a case report. J Med Case Rep 2010, 4:40.

16. Yamada T, Shinohara K, Katsuki K: A case of idiopathic hypereosinophilic syndrome complicated with disseminated intravascular coagulation. Am J Hematol 1998, 59:100-101.

17. Fukuta A, Hara T, Tsurumi H, Moriwaki H: Hypereosinophilic syndrome with DIC treated successfully with a combination of high-dose methylprednisolone and cyclosporin A [in Japanese]. Rinsho Ketsuek 2001, 42:1145-1147.

18. Yeung TF, Lau SW, Wong K: An unusual case of hypereosinophilic syndrome and disseminated intravascular coagulation. Chin Med J (Engl) 2005, 118:1582-1584.

19. Snyder MC, Lauter CB: Eosinophilic and neutrophilic leukemoid reaction in a woman with spindle cell sarcoma: a case report. J Med Case Rep 2010, 4:335.

20. Masi AT, Hunder GG, Lie JT, Michel BA, Bloch DA, Arend WP, Calabrese LH Edworthy SM, Fauci AS, Leavitt RY, Lightfoot RW Jr, McShane DJ, Mills JA, Stevens MB, Wallace SL, Zvaifler NJ: The American College of Rheumatology 1990 criteria for the classification of Churg-Strauss syndrome (allergic granulomatosis and angiitis). Arthritis Rheum 1990, 33:1094-1100.

21. van Dongen JJ, Langerak AW, Bruggemann M, Evans PA, Hummel M, Lavender FL, Delabesse E, Davi F, Schuuring E, Garcia-Sanz R, van Krieken JHJM, Droese J, González D, Bastard C, White HE, Spaargaren M, González M, Parreira A, Smith JL, Morgan GJ, Kneba M, Macintyre EA: Design and standardization of PCR primers and protocols for detection of clonal immunoglobulin and T-cell receptor gene recombinations in suspect lymphoproliferations: report of the BIOMED-2 Concerted Action BMH4-CT98-3936. Leukemia 2003, 17:2257-2317.

22. Umehara H, Okazaki K, Masaki Y, Kawano M, Yamamoto M, Saeki T, Matsui S, Sumida T, Mimori T, Tanaka Y, Tsubota K, Yoshino T, Kawa S, Suzuki R, Takegami T, Tomosugi N, Kurose N, Ishigaki Y, Azumi A, Kojima M, Nakamura S, Inoue D, The Research Program for Intractable Disease by Ministry of Health, Labor and Welfare (MHLW) Japan G4 team: A novel clinical entity, lgG4-related disease (IgG4RD): general concept and details. Mod Rheumatol.

23. Barkagan ZS, Golubenko VN: Severe eosinophilia in a patient with the inhibitory form of hemophilia B [in Russian]. Ter Arkh 1970, 42:56-58.

24. Suzuki S, Kida S, Ohira Y, Ohba T, Miyata M, Nishimaki T, Morito T, Kasukawa R, Hojyo H, Wakasa H: A case of Sjogren's syndrome accompanied by lymphadenopathy and IgG4 hypergammaglobulinemia [in Japanese]. Ryumachi 1993, 33:249-254

25. Kamisawa T, Okamoto A: Autoimmune pancreatitis: proposal of lgG4related sclerosing disease. J Gastroenterol 2006, 41:613-625.

26. Yamamoto $M$, Takahashi $H$, Ohara M, Suzuki C, Naishiro $Y$, Yamamoto $H$ Shinomura Y, Imai K: A new conceptualization for Mikulicz's disease as an IgG4-related plasmacytic disease. Mod Rheumatol 2006, 16:335-340.

27. Hamano H, Kawa S, Ochi Y, Unno H, Shiba N, Wajiki M, Nakazawa K Shimojo $\mathrm{H}$, Kiyosawa K: Hydronephrosis associated with retroperitoneal fibrosis and sclerosing pancreatitis. Lancet 2002, 359:1403-1404.

28. Takeda S, Haratake J, Kasai T, Takaeda C, Takazakura E: IgG4-associated idiopathic tubulointerstitial nephritis complicating autoimmune pancreatitis. Nephrol Dial Transplant 2004, 19:474-476.

29. Deshpande V, Khosroshahi A, Nielsen GP, Hamilos DL, Stone JH: Eosinophilic angiocentric fibrosis is a form of IgG4-related systemic disease. Am J Surg Pathol 2011, 35:701-706.

30. Khosroshahi A, Stone JH: A clinical overview of IgG4-related systemic disease. Curr Opin Rheumatol 2011, 23:57-66.

31. Pasquali T, Schoenfield L, Spalding SJ, Singh AD: Orbital inflammation in IgG4-related sclerosing disease. Orbit 2011, 30:258-260.

32. Takekawa M, Imai K, Adachi M, Aoki S, Maeda K, Hinoda Y, Yachi A Hypereosinophilic syndrome accompanied with necrosis of finger tips. Intern Med 1992, 31:1262-1266.

33. Costa JJ, Matossian K, Resnick MB, Beil WJ, Wong DT, Gordon JR, Dvorak AM, Weller PF, Galli SJ: Human eosinophils can express the cytokines tumor necrosis factor-alpha and macrophage inflammatory protein-1 alpha. J Clin Invest 1993, 91:2673-2684.

34. Campbell HD, Tucker WQ, Hort Y, Martinson ME, Mayo G, Clutterbuck EJ, Sanderson CJ, Young IG: Molecular cloning, nucleotide sequence, and expression of the gene encoding human eosinophil differentiation factor (interleukin 5). Proc Natl Acad Sci USA 1987, 84:6629-6633.

35. Kanbe N, Kurosawa M, Igarashi N, Tamura A, Yamashita T, Kurimoto F, Miyachi Y: Idiopathic hypereosinophilic syndrome associated with elevated plasma levels of interleukin-10 and soluble interleukin-2 receptor. Br J Dermatol 1998, 139:916-918.

36. Shinkai A, Yoshisue H, Koike M, Shoji E, Nakagawa S, Saito A, Takeda T, Imabeppu S, Kato Y, Hanai N, Anazawa H, Kuga T, Nishi T: A novel human CC chemokine, eotaxin-3, which is expressed in IL-4-stimulated vascular endothelial cells, exhibits potent activity toward eosinophils. J Immunol 1999, 163:1602-1610

37. Zwerina J, Bach C, Martorana D, Jatzwauk M, Hegasy G, Moosig F, Bremer J, Wieczorek S, Moschen A, Tilg H, Neumann T, Spriewald BM, Schett G, Vaglio A: Eotaxin-3 in Churg-Strauss syndrome: a clinical and immunogenetic study. Rheumatology (Oxford) 2011, 50:1823-1827.

38. Nakashima H, Miyake K, Moriyama M, Tanaka A, Watanabe M, Abe Y, Sato H, Nakamura S, Saito T: An amplification of IL-10 and TGF-beta in patients with IgG4-related tubulointerstitial nephritis. Clin Nephrol 2010, 73:385-391.

39. Tanaka A, Moriyama M, Nakashima H, Miyake K, Hayashida JN, Maehara T, Shinozaki S, Kubo Y, Nakamura S: Th2 and regulatory immune reactions contributes to lgG4 production and the initiation of Mikulicz's disease. Arthritis Rheum 2012, 64:254-263.

doi:10.1186/1752-1947-6-63

Cite this article as: Nagao et al: A patient with hypereosinophilic syndrome that manifested with acquired hemophilia and elevated IgG4: a case report. Journal of Medical Case Reports 2012 6:63. 